\title{
DESIGN OPTIMIZATION OF INDUCTION MOTOR BY GENETIC ALGORITHM AND COMPARISON WITH EXISTING MOTOR
}

\author{
Mehmet Çunkaş ${ }^{\mathrm{a},}$ and Ramazan Akkaya ${ }^{\mathrm{b}}$ \\ ${ }^{a}$ Department of Electronics and Computer Education, \\ Selçuk University, Konya, 42075, TURKEY \\ ${ }^{\mathrm{b}}$ Department of Electrical and Electronics Engineering, \\ Selçuk University, Konya, 42031, TURKEY \\ mcunkas@selcuk.edu.tr
}

\begin{abstract}
This paper presents an optimal design method to optimize three-phase induction motor in manufacturing process. The optimally designed motor is compared with an existing motor having the same ratings. The Genetic Algorithm is used for optimization and three objective functions namely torque, efficiency, and cost are considered. The motor design procedure consists of a system of non-linear equations, which imposes induction motor characteristics, motor performance, magnetic stresses and thermal limits. Computer simulation results are given to show the effectiveness of the proposed design process.
\end{abstract}

Key words-Design optimization, induction motor, genetic algorithm

\section{INTRODUCTION}

Induction motors are the most widely used in domestic, commercial and various industrial applications. Particularly, the squirrel cage type is characterized by its simplicity, robustness and low cost, which has always made it very attractive, and it has therefore captured the leading place in industrial sectors. As a result of its extensive use in the industry, induction motors consume a considerable percentage of the overall produced electrical energy. The minimization of electrical energy consumption through a better motor design becomes a major concern.

Many practical optimization problems in optimization of the electromagnetic devices have mixed (continuous and discrete) variables and discontinuities in search space. If the standard non-linear programming (NLP) techniques were to be used in such cases, then they would be computationally very expensive and inefficient. Some applications utilizing the standard NLP techniques include the design optimization of induction motor $[1,2]$. In recent years, GA's have been recognized as potent tools in design optimization of electrical machinery [3-6]. One of the most important advantages of the GA over the standard NLP techniques is that it is able to find the global minimum, instead of a local minimum, and that the initial attempts with different starting point need not be close actual values. Another advantage is that it does not require the use of the derivative of the function, which is not always easily obtainable or may not even exist, for example, when dealing with real measurements involving noisy data.

The aim of this paper is to give a further contribution in the optimum design of a three phase induction motor in manufacturing process, using three objective functions, namely torque (T), cost (C) and efficiency (E). Genetic Algorithm having feature of a unique search $[7,8]$ was then used for optimization processes. A design package has 
been developed specifically for a three-phase squirrel-cage type induction motor. Threephase squirrel-cage type induction motor having specifications $30 \mathrm{hp}, 380 \mathrm{~V}$, star connected, 4 pole, is chosen for comparison with three optimally designed motors. The basic specifications of these designs are similar and the same constraints are imposed upon the design process. Performance characteristics of the existing motor and three optimum designs are plotted on the same plane for comparison. Advantages and disadvantages of each design are then briefly discussed. It was observed that the cost optimization procedure was sensible, and the performance results obtained were promising.

\section{PROBLEM DEFINITION AND DESIGN APPROACHES}

The used equivalent circuit model of the motor is shown in Figure 1. The model is popular and well understood among engineers and, despite its shortcomings, offers reasonably good prediction accuracy with modest computational effort. This model is basically a per phase representation of a balanced poly-phase induction machine in the frequency domain, comprising six elements, or model parameters. The six impedances are stator resistance $R_{1}$, stator leakage reactance $X_{\sigma 1}$, magnetizing reactance $X_{\sigma \mathrm{m}}$, coreloss resistance $R_{m}$, rotor leakage reactance $X_{\sigma 2}$, and rotor resistance $R_{2}$. In this paper, the approaches and methods used to calculate the motor performances are based on the works of $[9,10]$.

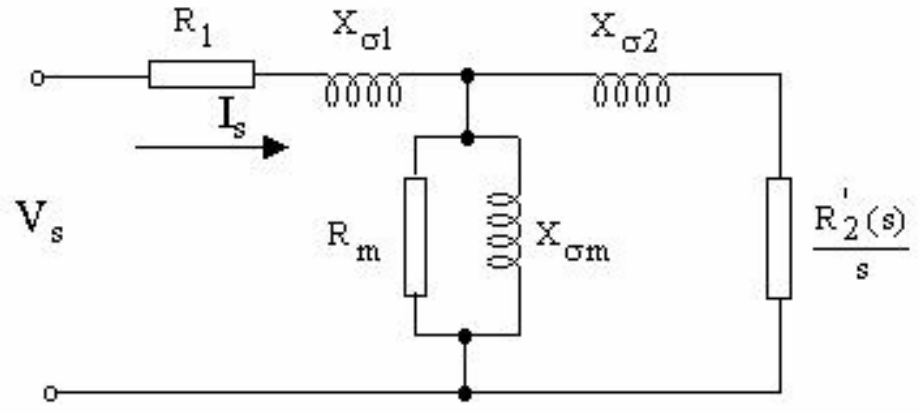

Figure 1. Equivalent circuit model of induction motor

To apply the GA approach, an objective function has to be defined to evaluate how good each motor design is. This objective function may include all the geometrical dimensions of the motor and a large subset of constraints (geometrical constraints) have to be formulated to ensure the physical feasibility of the motor. These objective functions are given in the following.

First objective function: The cost will be minimized. The cost variable consists of the laminations cost, copper cost, rotor-end-ring cost, and the core punching cost, which are used as the objective function of the optimization [11].

The weight of iron, $\mathrm{W}_{\mathrm{Fe}}$, is

$$
\mathrm{W}_{\mathrm{Fe}}=\frac{\mathrm{L}_{1} \mathrm{SF} \mathrm{D}_{\mathrm{o}}^{2} \mathrm{P}_{\mathrm{fe}}}{4} \text {, }
$$

the weight of the stator winding, $\mathrm{W}_{\mathrm{sw}}$, is

$$
\mathrm{W}_{\mathrm{sw}}=\mathrm{L}_{1} \mathrm{~S}_{1} \mathrm{~A}_{1 \mathrm{~m}} \mathrm{f}_{\mathrm{ew}} \mathrm{P}_{\mathrm{sw}} \text {, }
$$

and the weight of the rotor conductors, $\mathrm{W}_{\mathrm{rw}}$, is 


$$
\mathrm{W}_{\mathrm{rw}}=\mathrm{P}_{\mathrm{rw}}\left\{\frac{\pi \mathrm{w}_{\mathrm{a}}\left(\mathrm{D}_{\mathrm{r}}^{2}-\left(\mathrm{D}_{\mathrm{r}}-2 \mathrm{w}_{\mathrm{r}}\right)^{2}\right.}{2}+\mathrm{S}_{2} \mathrm{~A}_{\mathrm{b}}\left(\mathrm{L}_{2}-2 \mathrm{w}_{\mathrm{a}}\right)\right\},
$$

The punching $\operatorname{cost} \mathrm{C}_{\mathrm{p}}$ is estimated as $20 \%$ of the total cost. Thus the total manufacturing cost or also objective function is expressed as follows:

$$
\mathrm{C}_{\text {total }}=\mathrm{W}_{\mathrm{Fe}} \mathrm{Fe}_{\text {cost }}+\left(\mathrm{W}_{\mathrm{sw}}+\mathrm{W}_{\mathrm{rw}}\right) \mathrm{Cu}_{\mathrm{cost}}+\mathrm{C}_{\mathrm{p}} \text {, }
$$

Second objective function: The full load torque will be maximized. It should be noted that the objective function is defined as:

$$
\mathrm{T}_{\mathrm{n}}=\frac{60}{2 \pi \mathrm{n}_{1}} \mathrm{~m} \frac{\mathrm{V}_{\mathrm{s}}^{2}}{\left(\mathrm{R}_{1}+\tau_{1} \frac{\mathrm{R}_{2}}{\mathrm{~s}}\right)^{2}+\left(\mathrm{X}_{1}+\tau_{1} \mathrm{X}_{2}\right)^{2}} \frac{\mathrm{R}_{2}}{\mathrm{~s}},
$$

where the $\tau_{1}$ is the correction factor, the $\mathrm{n}_{1}$ is the synchronous speed.

Third objective function: The rated efficiency will be maximized, and the objective function is defined as:

$$
\eta=\frac{\mathrm{P}_{\text {out }}}{\mathrm{P}_{\text {input }}+\mathrm{P}_{\text {out }}},
$$

Table 1 shows the practicable domains and the resolution for the design parameters. To obtain an acceptable design, the design parameters need to be bound between upper and lower limit values. In the case presented here, ten design parameters, some of which is used in literature and affect induction motor's first order basic geometry is chosen.

Table 1 Design parameters and their limit values

\begin{tabular}{lllll}
\hline Design parameter & Description & Lower limit & Upper limit & Number of bit \\
\hline $\mathrm{x}_{1}$ & Number of turns per phase & 60 & 96 & 12 \\
$\mathrm{x}_{2}$ & Stator iron length $(\mathrm{cm})$ & 15 & 30 & 12 \\
$\mathrm{x}_{3}$ & End-ring width $(\mathrm{mm})$ & 15 & 30 & 12 \\
$\mathrm{x}_{4}$ & Stator interior diameter $(\mathrm{cm})$ & 18 & 25 & 12 \\
$\mathrm{x}_{5}$ & Stator slot height $(\mathrm{mm})$ & 18 & 38 & 8 \\
$\mathrm{x}_{6}$ & Stator slot width $(\mathrm{mm})$ & 7 & 12 & 8 \\
$\mathrm{x}_{7}$ & Air-gap $(\mathrm{cm})$ & 0.04 & 0.065 & 12 \\
$\mathrm{x}_{8}$ & Bridge thickness of rotor closed & 0.025 & 0.05 & 8 \\
& slot $(\mathrm{cm})$ & & & \\
$\mathrm{x}_{9}$ & Rotor bar diameter $(\mathrm{mm})$ & 6 & 10 & 8 \\
$\mathrm{x}_{10}$ & Stator exterior diameter $(\mathrm{cm})$ & 30 & 38 & 8 \\
\hline
\end{tabular}

\section{AN OVERVIEW OF GENETIC ALGORITHM}

In the most general sense, GA-based optimization is a stochastic search method that involves the random generation of potential design solutions and then systematically evaluates and refines the solutions until a stopping criterion is met. There are three fundamental operators involved in the search process of a genetic algorithm: selection, crossover, and mutation. The genetic algorithm implementation steps are shown as follows:

Step 1: Define parameter and objective function (Initializing)

Step 2:Generate first population at random

Step 3: Evaluate population by objective function 
Step 4: Test convergence. If satisfied then stop else continue.

Step 5: Start reproduction process (Selection, Crossover, Mutation)

Step 6: New generation. To continue the optimization, return to step 3.

Genetic algorithm that produces good results in many practical problems is composed of the following three operators:

Selection: Selection is a process in which individual strings are selected according to their fitness. The selection probability can be defined by

$\mathrm{P}_{\mathrm{j}}=\mathrm{F}\left(\mathrm{x}_{\mathrm{i}}\right) / \sum_{\mathrm{i}} \mathrm{F}\left(\mathrm{x}_{\mathrm{i}}\right)$

Where $\mathrm{P}_{\mathrm{j}}$ is selection probability and $\mathrm{F}\left(\mathrm{x}_{\mathrm{i}}\right)$ is objective function.

Crossover: This is the most powerful genetic operator. One of commonly used methods for crossover is single-point crossover. As shown in the following examples, a crossover point is selected between the first and the last bits of the chromosome. Then binary code to the right of the crossover point of chromosome goes $_{1}$ to offspring ${ }_{2}$ and chromosome $_{2}$ passes its code to offspring $1_{1}$. This operation takes place with a defined probability $\mathrm{P}_{\mathrm{c}}$ that statistically represents the number of individuals involved in the crossover process.

$$
\begin{aligned}
& \text { Chromosome }_{1}=0010010 \mid 101 \quad \text { Offspring }_{1}=0010010 \mid 100 \\
& \text { Chromosome }_{2}=0101011 \mid 100 \quad \text { Offspring }_{2}=0101011 \mid 101
\end{aligned}
$$

Mutation: This is a common genetic manipulation operator, and it involves, the random alteration of genes during the process of copying a chromosome from one generation to the next. Raising the ratio of mutations increases the algorithm's freedom to search outside of the current region of parameter space. Mutation changes from a " 1 " to a " 0 " or vice versa. It may be illustrated as follows.

$110000010 \rightarrow 110001010$

\section{IMPLEMENTATION OF THE OPTIMAL DESIGN PROCEDURE}

The formulation of the objective function is the following:

$F^{\prime}(x)=\left\{\begin{array}{lll}F(x)-P\left(g_{j}(x), r\right) & \text { If } & F(x)-P\left(g_{j}(x), r\right)>0 \\ 0 & \text { If } \quad F(x)-P\left(g_{j}(x), r\right) \leq 0\end{array}\right.$,

Where, $\mathrm{F}(\mathrm{x})$ is the objective function as the motor material cost, efficiency or torque, and moreover $\mathrm{r}$ is the penalty coefficient that is related to the value of objective function. The penalty function, $P\left(g_{j}(x), r\right)$, are expressed with respect to the type of inequality used. By means of exterior penalty function, constrained problems are converted to unconstrained problems by removing constraints. According to constraints, penalty function is defined as following;

$P\left(g_{j}(x), r\right)=\left\{\begin{array}{ll}r \sum_{j}\left[\max \left(0, g_{j}\right)\right]^{2} & j=1, \ldots 6 \\ r \sum_{j}\left[\min \left(0, g_{j}\right)\right]^{2} & j=7,8\end{array}\right.$,

According to Eq. (8), it is noticed that when the constraint inequality is satisfied, the penalty function becomes inactive. In the feasible region, the augmented objective function emphasizes the larger constraint violations and the optimization search tries to 
reduce these violations to zero. This would result in pushing the search into the feasible design region. Within this region all the constraints are satisfied and the optimization approach attempts to move the design into its best optimum solution.

However, in the electrical machine problem, the orders of magnitude of the various constraints are much different from one to another. Therefore, to have meaningful convergence criteria, constraint functions need to be normalized with respect to the specified objective function. This is necessary to ensure that constraints with higher values do not dominate over others. The normalized constraint functions in the penalty function are developed as shown in the following.

$g_{j \text { norm }}(x)=\frac{b_{j \text { ref }}-b_{j}}{b_{j}}, \quad \quad j=1,2, . .8$,

where $b_{j}$ ref is the value calculated from the current evaluation whereas $b_{j}$ is the expertdefined constant as shown in Table 2.

Table 2 Inequality constraints

\begin{tabular}{ll}
\hline Rated slip, $\mathrm{s}$ & $\leq\left(\mathrm{b}_{1}=0.05\right)$ \\
Stator yoke flux density, $\mathrm{B}_{\text {sy }}$ & $\leq\left(\mathrm{b}_{2}=1.6\right)$ \\
Rotor yoke flux density, $\mathrm{B}_{\mathrm{ry}}$ & $\leq\left(\mathrm{b}_{3}=1.6\right)$ \\
Stator teeth flux density, $\mathrm{B}_{\text {st }}$ & $\leq\left(\mathrm{b}_{4}=2\right)$ \\
Stator slot filling factor, $\mathrm{F}_{\mathrm{f}}$ & $\leq\left(\mathrm{b}_{5}=0.69\right)$ \\
Starting current to a rated current ratio, $\mathrm{I}_{\text {start }} / \mathrm{I}_{\mathrm{n}}$ & $\leq\left(\mathrm{b}_{6}=7\right)$ \\
Power factor, Cos $\varphi$ & $\geq\left(\mathrm{b}_{7}=0.8\right)$ \\
Pull-out torque to a rated torque ratio, $\mathrm{T}_{\mathrm{p}} / \mathrm{T}_{\mathrm{n}}$ & $\geq\left(\mathrm{b}_{8}=1.9\right)$ \\
\hline
\end{tabular}

The main purpose for imposing the constraint $b_{j}$ is to have the final design for practically feasible and acceptable. In general, the constraints are decided upon with great care taking into consideration the availability of materials, customers' requirements and manufacturing standards. In the present work, in Table 2, also referred to as the motor specifications and their constraint values are considered. Constraint values of variables can be expressed by following inequality.

$$
\begin{array}{ll}
\mathrm{g}_{1}(\mathrm{x})=\mathrm{s}-\mathrm{b}_{1} \leq 0 & \mathrm{~g}_{5}(\mathrm{x})=\mathrm{F}_{\mathrm{f}}-\mathrm{b}_{5} \leq 0 \\
\mathrm{~g}_{2}(\mathrm{x})=\mathrm{B}_{\text {sy }}-\mathrm{b}_{2} \leq 0 & \mathrm{~g}_{6}(\mathrm{x})=\mathrm{I}_{\text {start }} / \mathrm{I}_{\mathrm{n}}-\mathrm{b}_{8} \leq 0 \\
\mathrm{~g}_{3}(\mathrm{x})=\mathrm{B}_{\text {ry }}-\mathrm{b}_{3} \leq 0 & \mathrm{~g}_{7}(\mathrm{x})=\operatorname{Cos} \varphi-\mathrm{b}_{7} \geq 0 \\
\mathrm{~g}_{4}(\mathrm{x})=\mathrm{B}_{\text {st }}-\mathrm{b}_{4} \leq 0 & \mathrm{~g}_{8}(\mathrm{x})=\mathrm{T}_{\mathrm{p}} / \mathrm{T}_{\mathrm{n}}-\mathrm{b}_{6} \geq 0
\end{array}
$$

In Eq.(11), there are two different conditions of inequality constraint. Let us explain these conditions.

First condition: It is not given permission that some constraints $\left(\right.$ as $\left.g_{\mathrm{j}}(\mathrm{x}), \mathrm{j}=7,8\right)$ are the lower level. For example, high values for power factor are desired for good performance in induction motor. If the expert-defined constraint for power factor as shown in Table 2 were 0.8 , then anything less than that would be a violation. 
Second condition: It is not given permission that some constraints (as $g_{j}(x), j=1, . .6$ ) are the upper level. For example, stator yoke flux density may not exceed certain values on account of iron losses. If the expert-defined constraints for stator yoke flux density as shown in Table 2 was 1.6, then anything more than that would be a violation.

If a constraint for these conditions are violated, then the corresponding values of violation as defined in Eq. (9), are introduced into the calculation of $\mathrm{P}\left(\mathrm{g}_{\mathrm{j}}(\mathrm{x}), \mathrm{r}\right)$ in Eq. (8) If a constraint is not violated for these conditions, then the corresponding $\mathrm{P}\left(\mathrm{g}_{\mathrm{j}}(\mathrm{x}), \mathrm{r}\right)$ becomes zero, implying that there is no penalty associated with these constraints.

The software developed for the design optimization of the induction motor was prepared using Delphi high level programming language. This software can analyze and optimize motors or evaluates the cost and performance of design. Parameters of the motor or materials can be easily modified to investigate their effect on performance. Selection type and optimization type (torque, cost etc.) can be selected depending on user. The GA optimization algorithm was based on a roulette wheel selection, single point crossover, bit mutation, and elitism

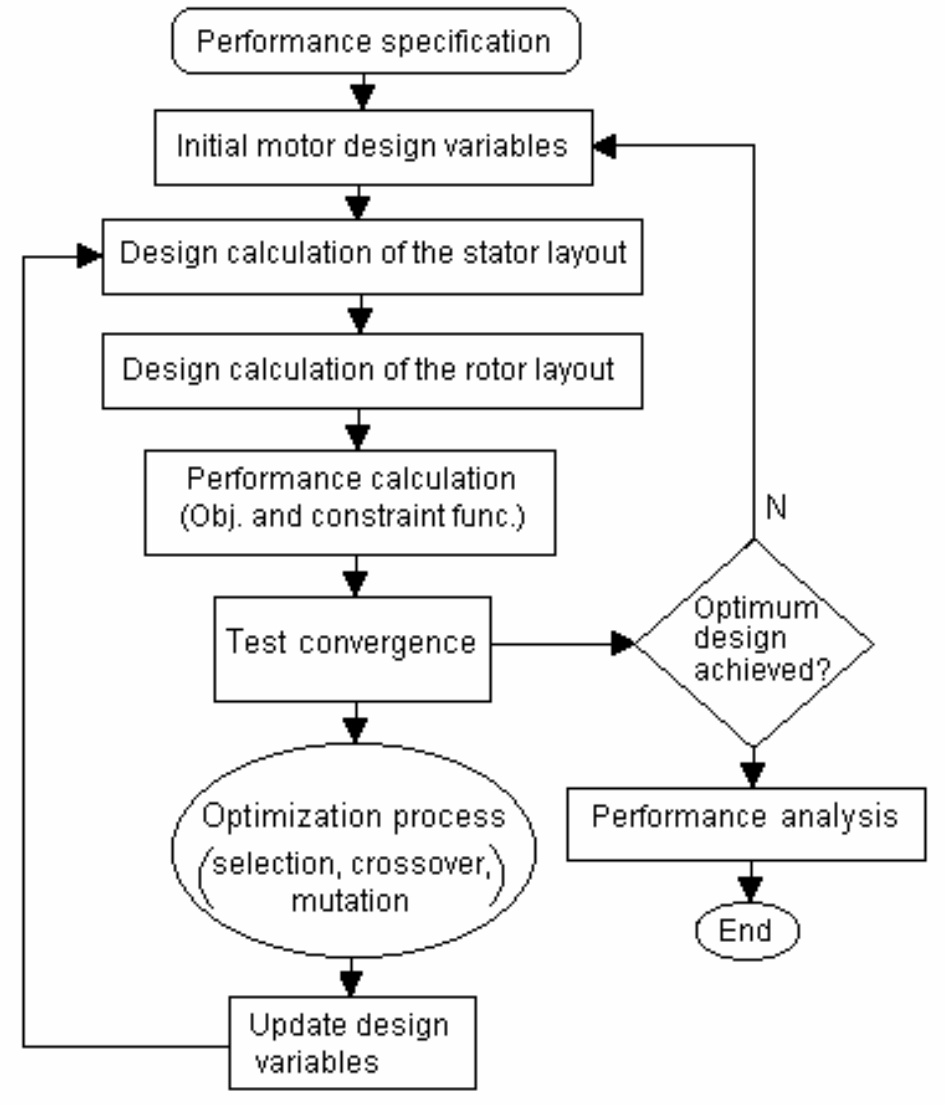

Figure 2. The flow chart for design optimization process

The flow chart of the design optimization procedure is depicted in Figure 2. Each block consists of number subroutines. Execution of the program starts with the performance specifications such as the initial motor design variables, the number of generations, population size, crossover rate, and mutation rate. Population size, number of generations, crossover rate and mutation rate can be selected depending on user. Each 
design parameter and penalty limits for penalty function can be varied within its domain. Then design parameter of the stator and rotor layout is calculated. This is followed by optimization process such as the selection, crossover, mutation and specification of the constraints. The design is evaluated for every individual of a population. The algorithm terminates after testing the specified convergence and optimum design achieving. At this point, the designer is offered the option to view the performance analysis for the proposed design. If the optimization are satisfied, then the design optimization process must be stop, otherwise continue the GA optimization process. The designer can improve the value of objective function reviewing constraint specifications.

\section{THE RESULTS AND DISCUSSION}

Table 3 shows the values for the ten design parameters for each optimization. According to the results in Table 3, the algorithm has returned an acceptable solution every time, which is indicated by a good value for objective with no constraint violations. Other variables of the induction motor are in turn reported in Table 4.

Table 3.The design parameter values obtained after optimization

\begin{tabular}{lllll}
\hline Design parameter & EM & T & E & C \\
\hline Number of turns per phase & 72 & 66 & 66 & 78 \\
Stator iron length $(\mathrm{cm})$ & 19.54 & 22.544 & 24.813 & 17.041 \\
End-ring width $(\mathrm{mm})$ & 25 & 23.482 & 27.704 & 29.395 \\
Stator interior diameter $(\mathrm{cm})$ & 22 & 22.381 & 21.827 & 21.196 \\
Stator slot height $(\mathrm{mm})$ & 33 & 25.529 & 26.078 & 29.45 \\
Stator slot width $(\mathrm{mm})$ & 10 & 11.705 & 10.647 & 11.980 \\
Air-gap (cm) & 0.042 & 0.0523 & 0.0649 & 0.0426 \\
Rotor slot path $(\mathrm{cm})$ & 0.05 & 0.029 & 0.0296 & 0.0481 \\
Rotor bar diameter $(\mathrm{mm})$ & 8.8 & 9.071 & 7.988 & 9.137 \\
Stator exterior diameter $(\mathrm{cm})$ & 37 & 34.823 & 34.017 & 34.010 \\
\hline
\end{tabular}

EM: Existing motor T: Torque optimization E: Efficiency Optimization C: Cost Optimization

Table 4. Comparison of the different designs and simulation results

\begin{tabular}{|c|c|c|c|c|}
\hline & EM & $\mathrm{T}$ & $\mathrm{E}$ & $\mathrm{C}$ \\
\hline Full load torque (Nm) & 138.27 & 147.89 & 137.01 & 139.91 \\
\hline Pull-out torque (Nm) & 323.501 & 412.67 & 377.36 & 359.8 \\
\hline Starting torque $(\mathrm{Nm})$ & 74.345 & 119.45 & 106.55 & 93.33 \\
\hline Power factor & 0.875 & 0.88 & 0.85 & 0.864 \\
\hline Efficiency (\%) & 88.91 & 89.00 & 90.98 & 86.50 \\
\hline Cost $(\$)$ & 480 & 486 & 513 & 360 \\
\hline Full load current (A) & 42.95 & 45.67 & 42.29 & 43.31 \\
\hline Starting current (A) & 176.32 & 229.45 & 208.53 & 197.83 \\
\hline Stator tooth flux density $(\mathrm{T})$ & 1.223 & 1.5 & 1.295 & 1.768 \\
\hline Rotor tooth flux density (T) & 1.622 & 1.59 & 1.478 & 2.03 \\
\hline Stator yoke flux density (T) & 1,185 & 1.28 & 1.231 & 1.523 \\
\hline Rotor yoke flux density (T) & 1.231 & 1.108 & 1.084 & 1.477 \\
\hline Air gap flux density $(\mathrm{T})$ & 0.623 & 0.584 & 0.544 & 0.691 \\
\hline Rotor current density $\left(\mathrm{A} / \mathrm{mm}^{2}\right)$ & 5.74 & 4.95 & 6.38 & 5.77 \\
\hline Temperature $\left({ }^{0} \mathrm{C}\right)$ & 75 & 75 & 75 & 75 \\
\hline Stator slot filling factor & 0.636 & 0.566 & 0.628 & 0.649 \\
\hline
\end{tabular}

EM: Existing motor T: Torque optimization E: Efficiency Optimization C: Cost Optimization 
According to these results in Table 4, while achieving performance improvements, the cost of the motor is reduced by about $25 \%$, which is a important reduction. Moreover, starting torque and pullout torque are desirably increased. On the other hand, a small decrease in efficiency and power factor is observed from the results. An essential remark here is that temperature rise of the motor is not known initially. Therefore, a fix value is given to the program. According to these results, it can be said that GA is suitable for motor design and can reach successful designs with lower cost, higher torque, and higher efficiency than the existing motor while satisfying almost every constraint.

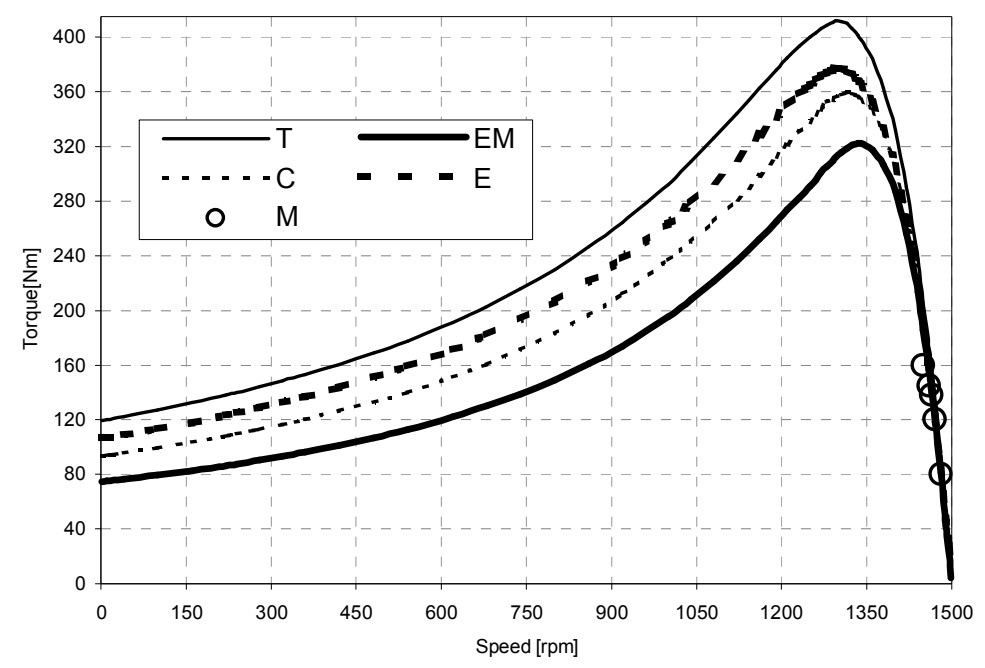

(a)

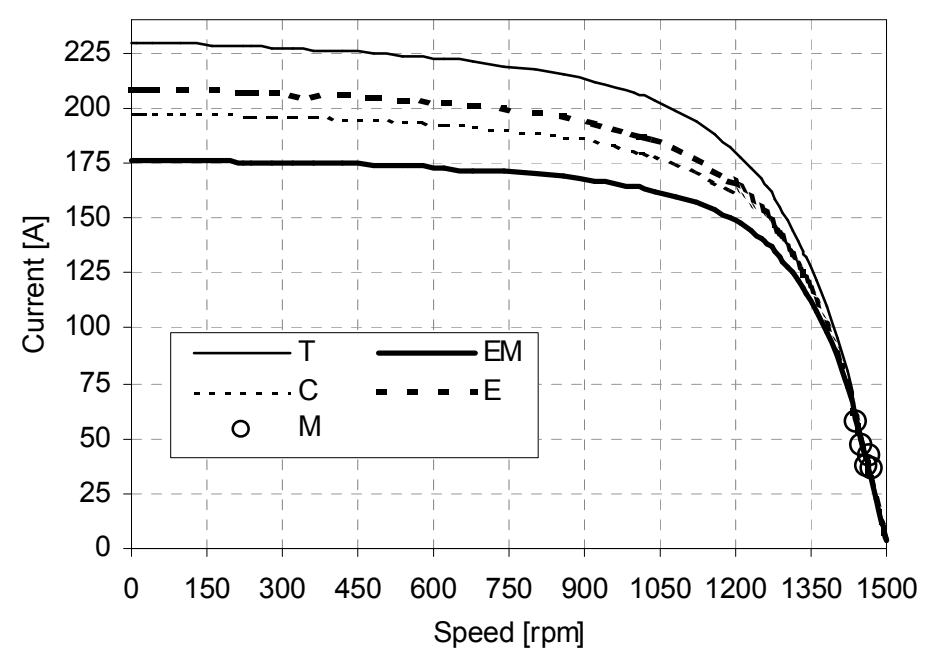

(b) 


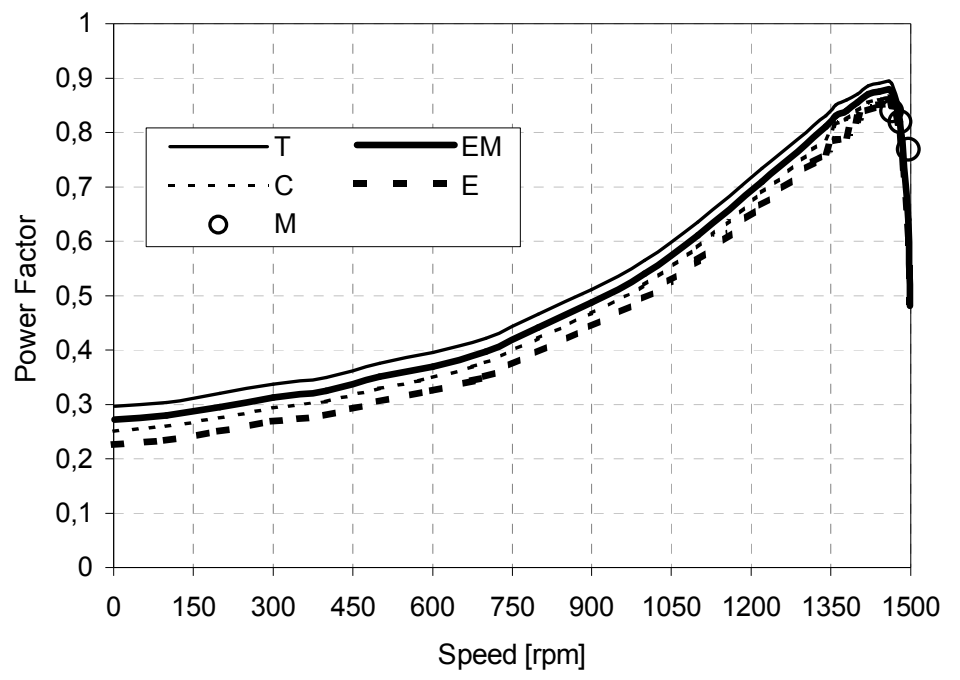

(c)

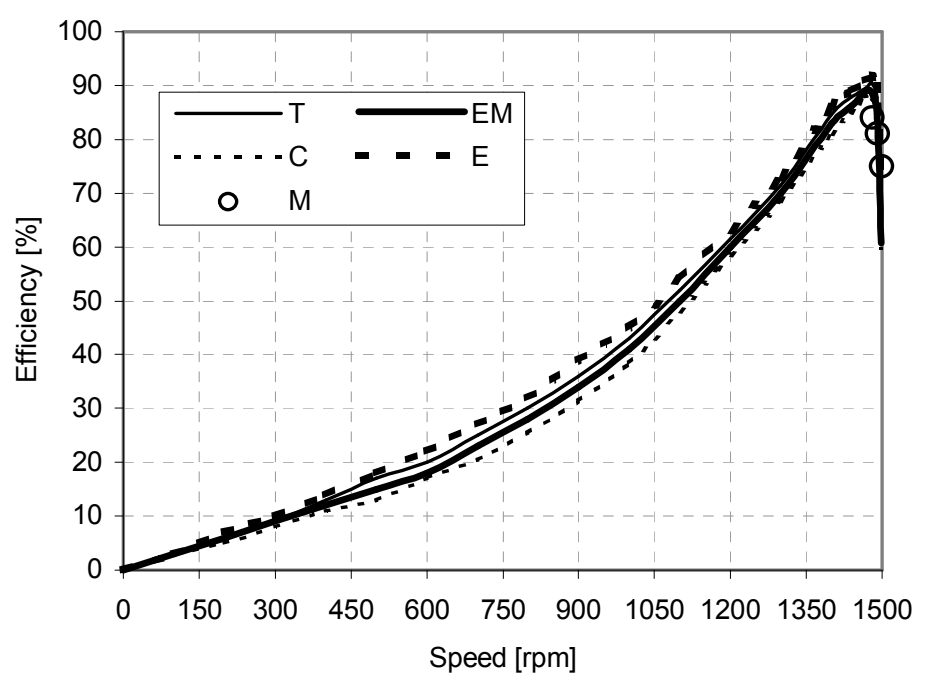

(d)

Figure 3 Performance Characteristics; a) Torque-speed, b) Current-speed, c) Power factor-speed and d) Efficiency-speed curves. (EM: Existing motor, T: Torque optimization, E: Efficiency Optimization, $\mathrm{C}$ : Cost optimization, M: Measured results)

Figure 3 depicts examples of performance characteristics of an existing design and three optimum designs as a function of the speed. According to Figure 3(a) starting torque of three optimum designs are always larger than that of the existing motor. Therefore, it exhibits better performance for larger loads. The full load torque at the cost and efficiency design is approximately equal while being the greater at the torque-based design. When Figure 3(b) is investigated, it can be seen that the starting current of the 
motor increase in respect of existing motor for three optimum designs. The highest variation of current is obtained for the torque-based design and the lowest variation is for the existing motor. According to Figure 3(c), a small increase is observed in the power factor at torque-based design. However, other designs are a decrease, which is acceptable that the reactive power consumption of the motor is suitable. When the Figure 3(d) is examined it can be said that the efficiency of the motor is approximately the same at existing motor and at the torque-based design while decreasing at cost-based design. Furthermore the motor efficiency was considerably increased at the efficiencybased optimization.

On the other hand, an important reduction in the cost of the motor was obtained in respect of existing motor at cost-based optimization. The cost of the torque-based design is almost similar to that of the existing design, but the efficiency-based design has larger cost. Comparison of four designs indicates that in general, efficiency optimization is the most expensive one. If the decrease at the power factor and the efficiency isn't taken into consideration, it can be said that cost-based design is better than the other one, resulting in a good performance regarding the cost of different component and their dependencies on region, manufacturer and time. The performance of the optimized motor is seen to be improving respectably when compared with the existing motor.

\section{CONCLUSION}

This paper has compared three different optimally designed three-phase squirrel-cage induction motors with an existing motor of the same rating. An optimization technique based on GAs has been applied to the design of $30 \mathrm{hp}$ three-phase induction motor. A package program that analyzes and optimizes induction motors and evaluates the cost and performance of the designs has been developed. Comparison of the final optimum designs with the existing design indicates that the gain of the proposed performance is even better than expected. In this instance, higher starting and pullout torques, larger efficiency and finally a lower cost for induction motor designs can be pointed out. While achieving performance improvements, the cost of the motor is reduced by about $25 \%$, which is an important result. The optimum cost-based design is the best in this respect, regarding the cost of different components and their dependencies on region, manufacturer and time.

\section{List of symbols}

$C u_{\text {cost }} \quad$ cost of unit weight of copper;

$D_{e} \quad$ stator diameter at centers of stator slots;

$D_{o} \quad$ stator outer diameter;

$D_{r} \quad$ rotor diameter;

$\mathrm{Fe}_{\text {cost }} \quad$ cost of unit weight of iron;

$f_{\text {ew }} \quad$ end winding factor;

$L_{1}, L_{2} \quad$ axial length of stator and rotor, respectively;

$m \quad$ number of phase;

$P_{f e} \quad$ density of the iron sheet;

$P_{s w}, P_{r w} \quad$ density of stator and rotor conductors, respectively;

$P_{\ell c u} \quad$ total copper losses of stator and rotor;

$P_{\ell f e} \quad$ total iron losses; 
$s \quad$ slip;

$S F \quad$ stacking factor;

$S_{1}, S_{2} \quad$ number of stator and rotor slot, respectively;

$w_{a}, w_{r} \quad$ rotor end rings axial and radial width, respectively;

\section{REFERENCES}

1. R Fci, E.F. Fuchs, H. Huaugh, Comparison of two optimization techniques for the design of a three-phase induction motor design, IEEE Trans on Energy Conv.;4(4):651-9, 1989.

2. J. Faiz, M.B.B. Sharifian, Optimal design of three phase induction motors and their comparison with a typical industrial motor. Int. J. of Comp. and Elect. Eng. 27:133$144,2001$.

3. G.F. Üler, O.A. Mohammed, C.S. Koh,. Utilizing genetic algorithms for the optimal design of electromagnetic devices, IEEE Trans. on Magnetics, Vol. 30, No. 6, pp. 4296-4298, 1994.

4. N. Bianchi, S. Bolognani, Design optimization of electric motors by genetic algorithm. IEE Proc. Electr. Power Appl., 145: 475-483, 1998.

5. J.P. Wieczorek, Ö. Göl, Z. Michalewicz, An evolutionary algorithm for the optimal design of induction motors. IEEE Trans. On Magnetics, Vol. 34 No.6, pp. 38823887, 1998.

6. M. Çunkaş, R. Akkaya., O. Bilgin, Cost optimization of submersible motors using a genetic algorithm and a finite element method, Int. J. of Adv. Manuf. Tech., in press, 2006.

7. D.E. Goldberg, Genetic Algorithms in Search, Optimisation, and Machine Learning, Addison Wesley, New York, 1989.

8. Z. Michalewicz, Genetic algorithms + Data Structures $=$ Evolution Programs, $2^{\text {nd }}$ ed., Springer-Verlag, New York, 1994.

9. S.J. Chapman, Electric machinery and power system fundamentals, McGraw-Hill, New York, 2002.

10. C.G. Veinott, Theory and Design of Small Induction Motors, McGraw-Hill, New York, 1959.

11. J. Faiz, M.B.B. Sharifian, A. Keyhani, A. Proca, Performance comparison of optimally designed induction motors with aluminum and copper squirrel-cages, Elect. Mach. and Power Sys, 28:1195-1207, 2000. 